\title{
QUIZ CASE
}

\section{Trauma imaging of the cranio-cervical junction}

S K Misser, MB ChB, FC RAD (D) SA

T Z Mngoma, MBA, MB ChB, FFRAD (SA)

Lake Smit and Partners, Durban

M Roux, MB ChB, FCS (SA)

Entabeni Hospital, Durban

Corresponding author: Shalen Misser (misser@lakesmit.co.za)

S Afr J Rad 2012;16(3):111-113. DOI:10.7196/SAJR.773

\section{Presentation}

A 5-year-old boy presented to A\&E after a motor vehicle accident in which he was an unrestrained passenger. He was found to have

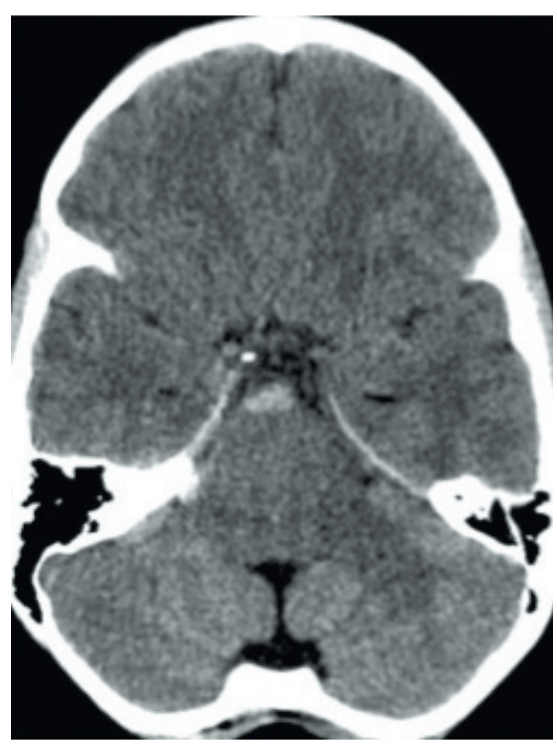

Fig. 1. Axial CT scan at the level of the pons.

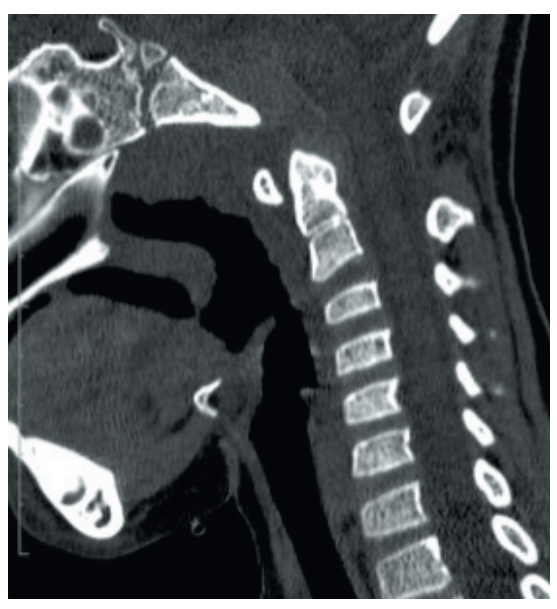

Fig. 3. Sagittal CT reformat of the CCJ. quadriparesis, with the following images of the cranio-cervical junction (CCJ) obtained on admission.

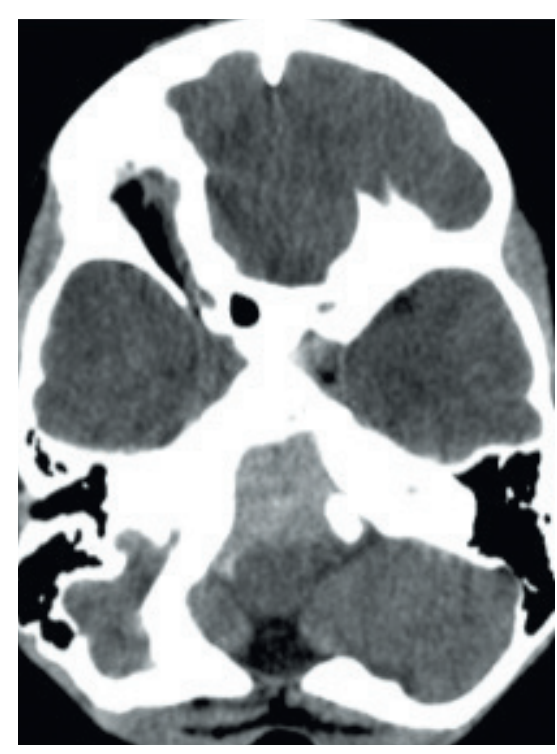

Fig. 2. Axial CT scan at the level of the foramen magnum.

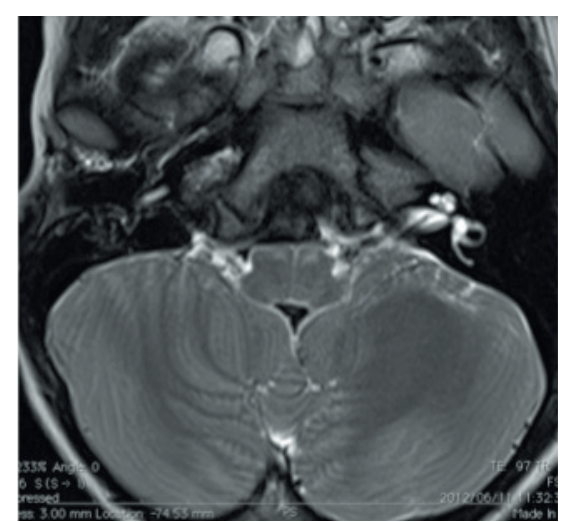

Fig. 4. Axial T2-weighted MRI at the CCJ. 


\section{QUIZ CASE}

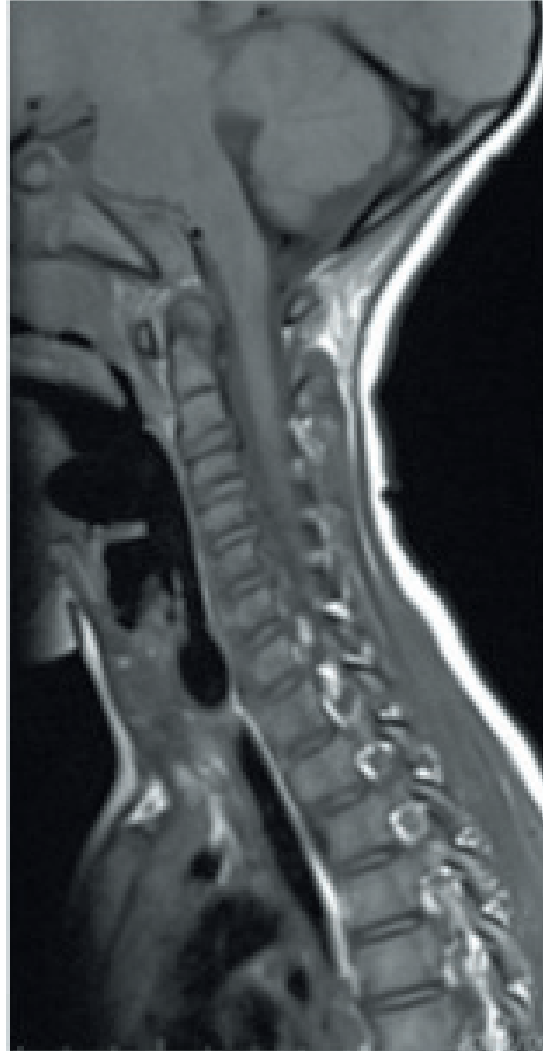

Fig 5. Midline sagittal T1-weighted MRI at the CCJ.

Describe the relevant findings and provide the most appropriate clinical diagnosis. Please submit your response to Dr Misser at misser@lakesmit.co.za not later than 11 November 2012. The winning

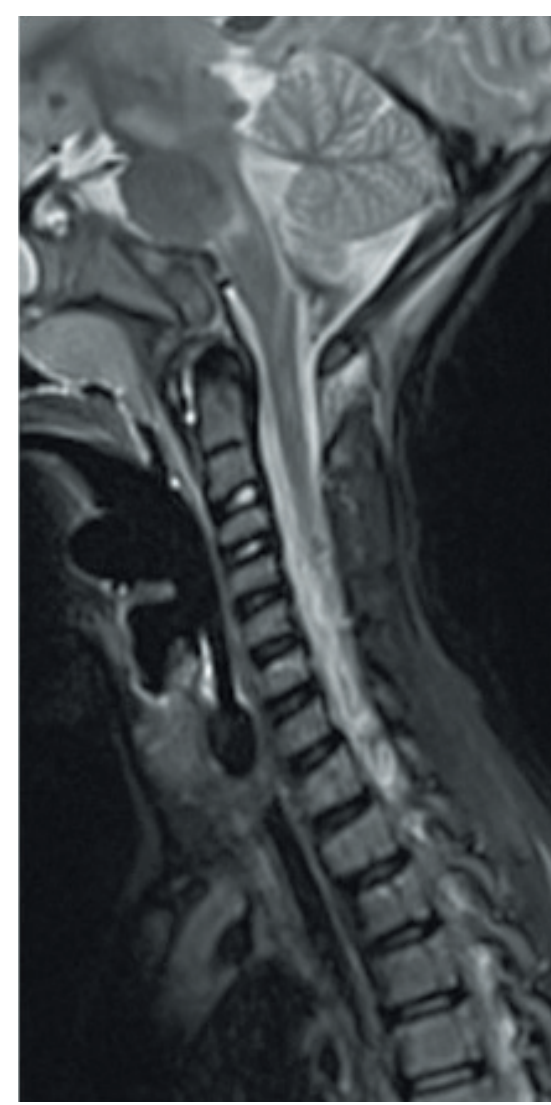

Fig. 6. Midline sagittal T2-weighted MRI at the CCJ.

respondent will receive a R1 000 award from the RSSA. A detailed diagnosis and discussion will be presented in the next issue of the SAJR. 